Egyptian

Orthodontic Journal

\title{
THE EFFECTS OF GINGIVAL FIBROTOMY ON THE RATE OF CANINE RETRACTION AND ANCHORAGE LOSS
}

\author{
Shacker Muhsen Al-Magaleh ${ }^{1}$, Maha Abu Khedr'2, \\ Hanan A. Ismail ${ }^{3}$, Walid A. El-Kenany ${ }^{4}$ \\ ABSTRACT
}

Introduction: This study investigated the effects of the gingival fibrotomy on the rate of canine retraction and anchorage Coss. Methods: A split-mouth design RCT study was conducted in

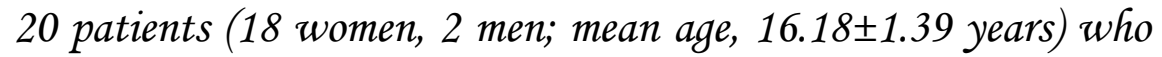
need maxillary first premolars extraction and canines retraction. Fibrotomy was randomly allocated to one canine and the other used as control. Canines were retracted by closed coil springs applying $150 \mathrm{~g}$ in both sides. Rate of canine retraction and rate of anchorage loss were assessed using dental casts taken every 4 weeks. Results: No statistical significant difference was detected between both sides in the rate of canine retraction. The rate of anchorage loss showed statistically significant but clinically insignificant difference at the period of 4 and 16 weeks. Conclusion: Gingival fibrotomy around the upper canine in combination with extraction of the first premolar resulted in the same rate of canine retraction and anchorage loss in comparison to extraction of the first premolar only.

1- Assistant lecturer, Department of Orthodontics, Faculty of Dentistry, Ibb University, Ibb, Yemen.

2 - Professor, Department of Periodontology, Faculty of Dentistry, Alexandria University, Alexandria, Egypt.

3 - Professor, Department of Orthodontics, Faculty of Dentistry, Alexandria University, Alexandria, Egypt.

4 - Professor, Department of Orthodontics, Faculty of Dentistry, Alexandria University, Alexandria, Egypt. 
Egyptian

Orthodontic Journal

\section{INTRODUCTION}

The sequels of prolonged orthodontic treatment involve high incidence of caries $^{1}$ and external apical root resorption ${ }^{2}$ which compromise treatment outcome. Pursuit of accelerating orthodontic tooth movement is a concern for many recent researches.

A full periosteal flap elevation has been claimed to produce a transient burst of regional remodeling known as regional accelerated phenomenon (RAP). ${ }^{3}$ The effect of merely gingival fiberotomy on tooth mobility was attributed to the incision of transseptal fibers splinting the teeth ${ }^{4}$, proposing a resistance ${ }^{5}$ or inhibitory ${ }^{6}$ effect of gingival tissue to the orthodontic tooth movement. Recently gingival fiberotomy has been shown to increase alveolar bone resorption during orthodontic tooth movement in rats, which suggest that gingival fiberotomy solely accelerates orthodontic tooth movement and diminishes relapse. ${ }^{7}$ However, a clinical study by Kalra et al conflicted with that and showed insignificant effect of the gingival fiberotomy on the rate of canine distal movement. ${ }^{8}$ Sharma and Kotrashetti evaluated the effect of fiberotomy in accelerating tooth movement versus corticotomy and conventional treatment. Fibrotomy induced faster rate of retraction compared to the conventional treatment; however, corticotomy resulted in more swelling than fiberotomy. ${ }^{9}$

The purpose of this study was to investigate the effect of gingival fiberotomy of the supra-alveolar fibers on the rate of tooth movement during upper canine retraction.

\section{MATERIAL AND METHODS}

A split mouth prospective randomized control trial that was approved by Biostatic Department, Medical Researches Center, Alexandria was performed. The sample size was calculated in Biostatic Department, Medical Researches Center, Alexandria, depending on Mezomo et al study ${ }^{10}$. The sample size of 17 subjects was estimated to achieve a power of $99 \%$, three subjects have been added to overcome attrition rate. A total of 20 subjects were involved in the study. Inclusion criteria included malocclusion that requires therapeutic extraction of upper first premolars and symmetrical mechanics for canines retraction 
on maximum anchorage as part of orthodontic treatment with fixed appliance, full upper permanent dentition to the second molars and good oral hygiene detected by plaque index. Patients with clinical evidence of gingival or periodontal inflammation (assessed by papilla bleeding index or loss of attachment) were excluded. An approved informed consent by Ethical Committee Council Faculty of Dentistry Alexandria University was used.

Full bonding with 0.022-inch Roth prescription appliance (mini 2000, Ormco®, Sybron Dental Specialities Inc., CA, USA) and banding to the first and second molars were done. Levelling and alignment was accomplished to a passive $0.016 \times 0.022$-inch stainless steel wire. The subjects were randomly assigned to the split mouth intervention using Excel software program (Microsoft, Inc, Redmond, WA, USA) by a neutral staff member. The randomization lists were concealed in closed envelops and sent to the surgeon. Interventions involved one side with extraction of the first premolar and the other side with gingival fibrotomy around the canine followed by extraction of the first premolar. The gingival fibrotomy was accomplished according to Edwards approach ${ }^{11}$ (Figure 1).

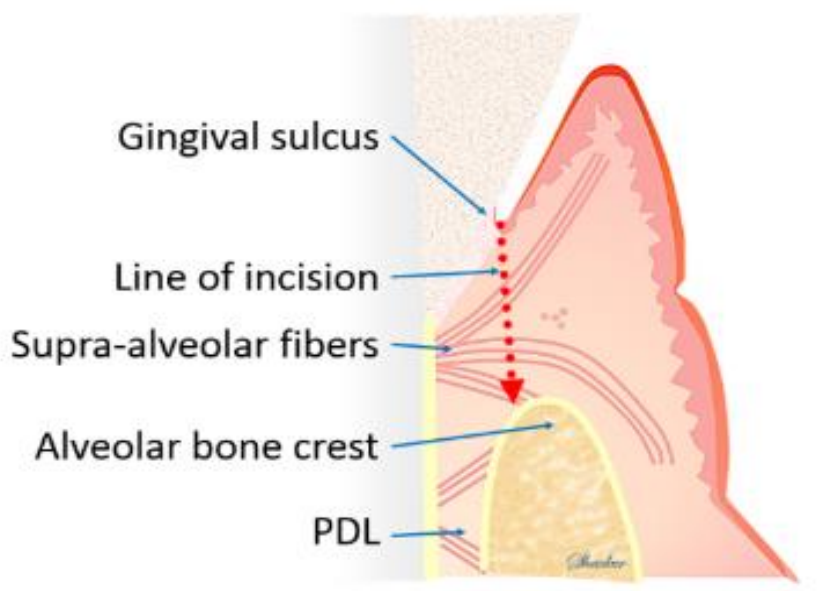

Figure 1: The line of incision through the supracrestal fibers. 
Egyptian

Orthodontic Journal

The posterior dental segment in each side was ligated to provide maximum anchorage for canine retraction. Immediately after fibrotomy, NiTi closed coil springs of $6 \mathrm{~mm}$ long (Locking Closed Coil Spring, 3M Unitek $^{\mathrm{TM}}$, California, USA) was stretched between the canine and the first molar to give an initial force of 150 gram on each side by force gauge (Orthodontic Tensiometer 25-250gf, Morelli orthodontia, São Paulo, Brasil) for canine retraction along a continuous main arch wire of $0.016 \times 0.022$-inch stainless steel wire.

Before extraction, an alginate impression was taken for the upper arch to make the base line dental cast. After that, subjects were recalled every 4 weeks during canine retraction until one canine touched the second premolar. In every appointment an alginate impression was taken to the upper arch. The impression was poured immediately with dental stone. After its setting the dental cast was trimmed and labelled with the date and subject's code.

For dental cast measurements, we used a modification of the acrylic plugs that were used in numerous researches. ${ }^{10,12-15} \mathrm{We}$ named it the spider plug. The base line dental cast was used to fabricate the spider plug (Figure 2 and Figure 3). It consisted of an acrylic part and four reference wires (Figure 4, a). The acrylic part was seated on the most stable region of the upper dental cast. This region extends from the medial $2 / 3$ of the third rugae dorsally to the line contacting the distal surface of the upper first molars.16-18 The acrylic plug was sequentially seated on the dental casts according to ordinal date. The plug was adapted to the dental cast by best fit. Measurements were taken directly on every dental cast (Figure 4, b) on both sides using a digital caliber (Lot 1003 digital caliper, the international orthodontics service, Houston, USA).

Statistical analysis was performed with Excel software (version 2013, Microsoft, Inc, Redmond, WA, USA) and SPSS (version 20.0; IBM Corp. Chicago, IL, USA). The significant level was set at $\mathrm{P}$ value $\leq 0.05$. Intra class correlation was used to assess intra observer reliability (Appendix I). 


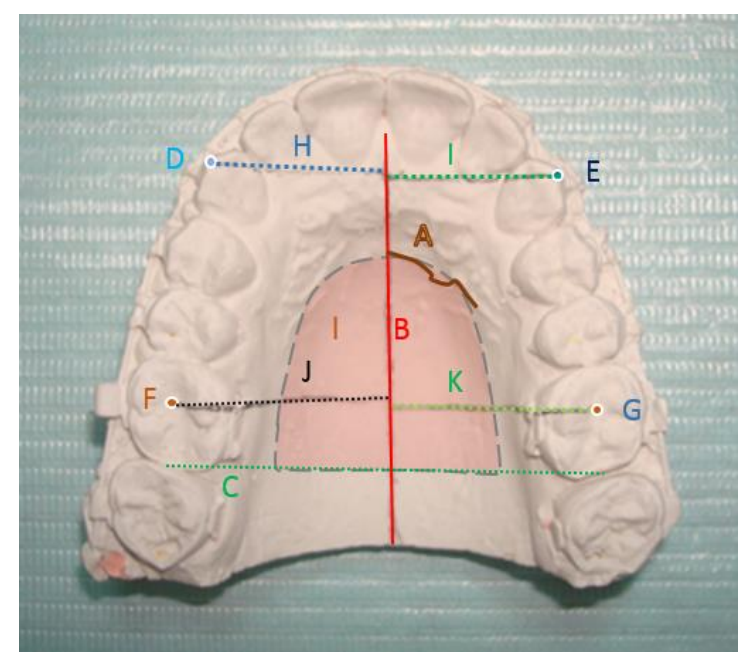

Figure 2: Reference land marks and lines of dental cast analysis: A) medial part of the left third rugae, B) the vertical reference line, C) The distal border line, D) cusp tips of the right canine, E) cusp tips of the left canine, F) central fossa of the right first molar, G) central fossa of the left first molar, H) and I) perpendicular lines from the canines tips to the vertical reference line, J) and $\mathrm{K}$ ) perpendicular lines from the first molars central fossae to the vertical reference line, L) the palatal plug area in red shadow.

\section{RESULTS}

Twenty subjects were recruited in this study with mean age of $16.18 \pm 1.39$ years old. Table I shows the means and standard deviations of the monthly rate of canine retraction and anchorage loss. In 6 subjects one upper canine was fully retracted after 20 weeks, in 6 subjects after 24 weeks, in 6 subjects after 28 weeks and in 2 subjects after 32 weeks. There wasn't any statistically significant difference between the fibrotomy and the control sides in the rate of canine retraction at any period, beside that the average of the canine retraction of both sides shows insignificant difference. There were statistically significant differences between the fibrotomy and the control sides in the anchorage loss at period of 4 weeks and 16 weeks of canine retraction. However the average of all periods of both sides shows insignificant difference. 


\section{Egyptian}

Orthodontic Journal
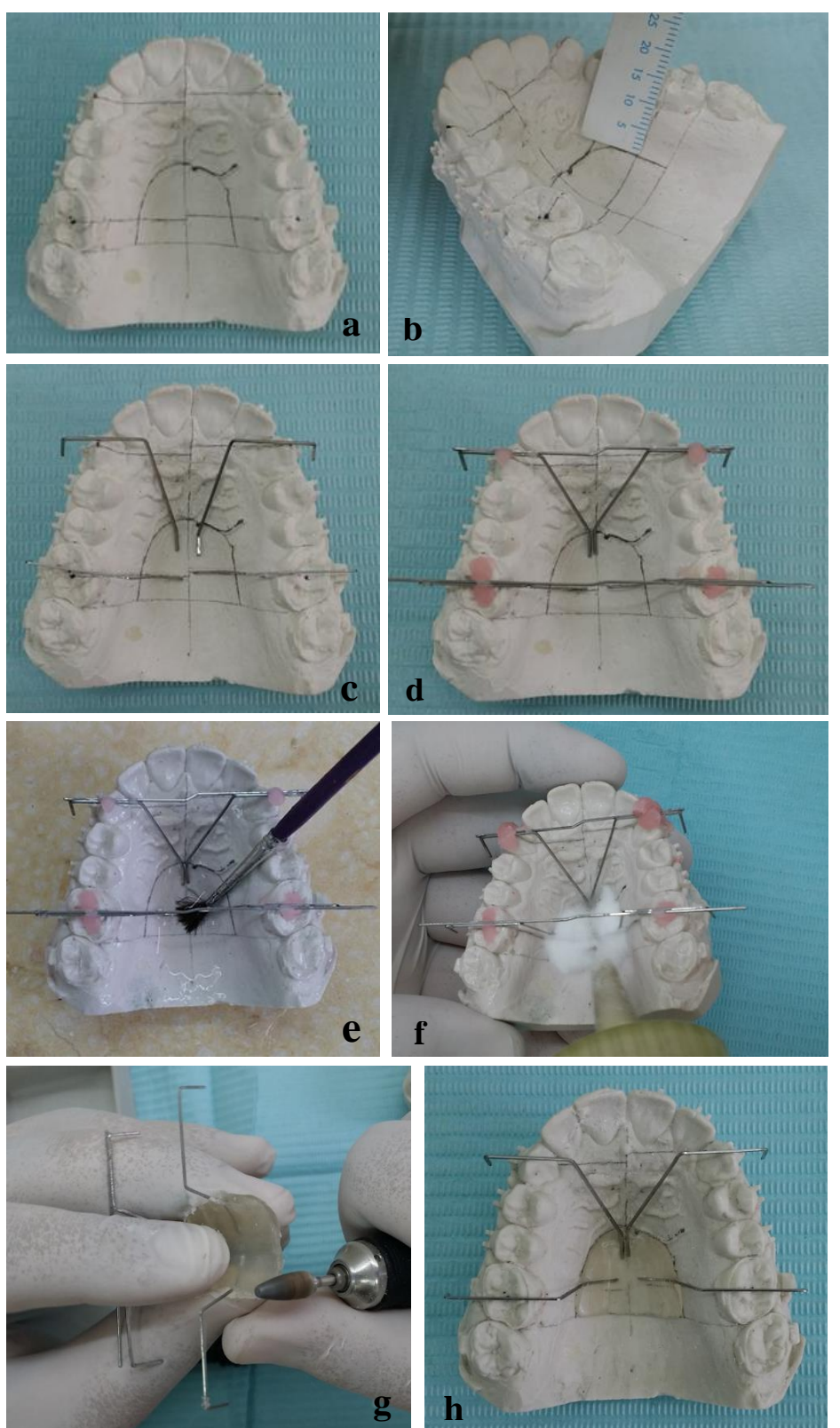

Figure 3: a) The base line dental casts with reference landmarks, b) the palatal area of the plug $10 \mathrm{~mm}$ from the free gingiva, c) and d) metal arms fixed with guiding wires, e) application of separating media, f) salt and pepper technique of acrylic fabrication, g) finishing and polishing and $\mathrm{h}$ ) plug readjustment. 

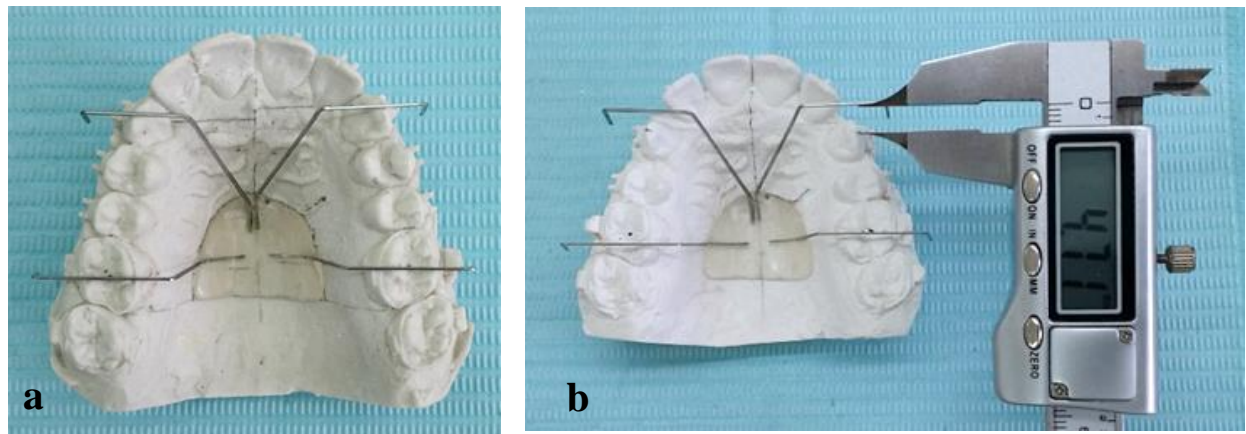

Figure 4: a): The base line dental cast with the spider plug, metal arms extends occlusal to the cusp tips of the canines and the central fossae of the first molars. b): The measurements were taken by a digital caliper as the perpendicular distance between the reference wire and the landmark.

Table I: The monthly rate of canine retraction and anchorage loss

\begin{tabular}{|c|c|c|c|c|c|c|c|c|c|c|c|}
\hline & \multicolumn{6}{|c|}{ Rate of canine retraction } & \multicolumn{5}{|c|}{ Rate of anchorage loss } \\
\hline \multirow[t]{2}{*}{ Time } & \multirow[b]{2}{*}{$\mathrm{n}$} & \multicolumn{2}{|c|}{ Fibrotomy side } & \multicolumn{2}{|c|}{ Control side } & \multirow{2}{*}{$P$ value } & \multicolumn{2}{|c|}{ Fibrotomy side } & \multicolumn{2}{|c|}{ Control side } & \multirow{2}{*}{$P$ value } \\
\hline & & Mean & SD & Mean & $\mathrm{SD}$ & & Mean & SD & Mean & $\mathrm{SD}$ & \\
\hline 4 weeks & 20 & 1.10 & 0.71 & 1.17 & 0.64 & 0.667 & 0.49 & 0.41 & 0.71 & 0.47 & $0.007 *$ \\
\hline 8 weeks & 20 & 1.08 & 0.53 & 0.96 & 0.51 & 0.395 & 0.4 & 0.25 & 0.37 & 0.3 & 0.746 \\
\hline 12 weeks & 20 & 1.09 & 0.64 & 0.96 & 0.48 & 0.452 & 0.41 & 0.28 & 0.33 & 0.21 & 0.302 \\
\hline 16 weeks & 20 & 0.94 & 0.47 & 0.96 & 0.38 & 0.891 & 0.24 & 0.17 & 0.43 & 0.26 & $0.001 *$ \\
\hline 20 weeks & 20 & 1.08 & 0.64 & 0.96 & 0.57 & 0.527 & 0.34 & 0.26 & 0.32 & 0.23 & 0.72 \\
\hline 24 weeks & 14 & 0.82 & 0.43 & 0.86 & 0.45 & 0.814 & 0.29 & 0.23 & 0.22 & 0.18 & 0.295 \\
\hline 28 weeks & 8 & 0.42 & 0.25 & 0.60 & 0.39 & 0.201 & 0.24 & 0.23 & 0.36 & 0.22 & 0.381 \\
\hline 32 weeks & 2 & 0.50 & 0.44 & 0.43 & 0.49 & 0.933 & 0.08 & 0.035 & 0.16 & 0.1 & 0.3 \\
\hline Average & 20 & 1.0004 & 0.23 & 0.96 & 0.15 & 0.348 & 0.36 & 0.11 & 0.4 & 0.13 & 0.056 \\
\hline
\end{tabular}

\section{DISCUSSION}

Tracking down new approaches for accelerating orthodontic tooth movement has driven researchers for invasive surgical procedures. Since Harold Frost ${ }^{19}$ introduced the term Regional Accelerating Phenomenon 
Egyptian

Orthodontic Journal

(RAP), orthodontic researchers have used this term for clarification of the biology under acceleration of tooth movement by surgical procedures.

Gingival fibrotomy was correlated with reducing the splinting ${ }^{4}$ and inhibitory effect ${ }^{5,6}$ of the gingival tissue but the biological changes underling this effect was not fully understood. On the other hand, a burst of osteoclastic alveolar bone remodeling and soft-tissue healing was evident even by merely a full periosteal flap elevation or a gingival fibrotomy. $3,7,20,21,22,23,24,25,26$. This split mouth randomized clinical trial investigated the effect of fibrotomy of the supracrestal gingival fibers around the upper canines on the rate of canine retraction.

In order to assess the rate of canine retraction on the progress models, a palatal plug (the spider plug) was constructed with reference wires. The spider plug was a modification of the acrylic plug used in numerous researches. ${ }^{12,} 10,13,14,15$. Our modification involved seating the acrylic part on the most stable region ${ }^{16,17,18}$ of the upper dental cast, besides using a stiff rectangular wire $(0.018 \times 0.025$-inch stainless steel wire) to fabricate the reference wires, which were bent to pass perpendicularly to the midsagittal plan at the level of the occlusal plan. To make sure that the reference wires were stable during measurements, the wires were checked on the base line dental cast every time before assessment of a new progress dental cast.

In measurements of the linear canine movement, we did not use the mesial or distal aspect of the tooth as the canine is pear shaped and susceptible to rotation which might affect the measurements. We used instead the cusp tips of the canines, when it was difficult to detect the cusp tip of the canine, the long axis of the buccal surface of the crown was used as a guide line. In contrast for the first molar measurements, it was difficult to detect the cusp tips accurately so we used the mesial aspect instead.

The average rate of canine retraction per 4 weeks intervals was $1.00 \pm 0.23 \mathrm{~mm} / \mathrm{month}$ for the fibrotomy side and $0.96 \pm 0.15 \mathrm{~mm}$ for the control side. The rate of canine retraction in the current study was in agreement with the conventional treatment; in general the mean rate of canine retraction per 28 days using conventional bracket and 150 gram of 
Egyptian

Orthodontic Journal

force coil spring was $1.17 \mathrm{~mm} .{ }^{27}$ No significant difference was reported between the fibrotomy side and the control side in any interval. All patients had passed 20 weeks before an upper canine was fully retracted in any patient. Along the 20 weeks, the repeated measurements of the rate of canine retraction showed insignificant changes on either the fibrotomy side or the control side. These finding suggested that the gingival fibrotomy produces RAP that is not enough to produce any significant change in the monthly rate of the canine retraction throughout the period of canine retraction. These results agree with the findings of Kalra et al ${ }^{8}$ who reported insignificant difference between the amount of canine retraction during 3 months after extraction of first premolars combined with gingival fibrotomy around the canines $(2.5 \pm 0.75 \mathrm{~mm})$ or after extraction only $(2.14 \pm 0.96 \mathrm{~mm})$.

In the current study, the difference between the two sides in the rate of anchorage loss wasn't statistically significant except at the period of 4 weeks and 16 weeks of canine retraction. On average, the monthly rate of anchorage loss showed insignificant difference between the fibrotomy side $(0.36 \mathrm{~mm})$ and the control side $(0.4 \mathrm{~mm})$. The anchorage loss in the our study was more than that reported by Kalra et al ${ }^{8}$ who reported insignificant difference between the fibrotomy side and the control sides with $0.11 \pm 0.33 \mathrm{~mm}$ mesial movement of first molars in the fibrotomy side and $0.16 \pm 0.35 \mathrm{~mm}$ in the control side after 3 months.

The RAP was associated with anxious stimulus of the soft and hard tissues. ${ }^{19}$ The limitation in our investigation is that we could not detect if the RAP associated with the extraction in both sides masked the RAP associated with gingival fibrotomy on the intervention side.

On the basis of the results of the current study we concluded that gingival fibrotomy around the upper canine in combination with extraction of the first premolar resulted in the same rate of canine retraction in comparison to extraction of the first premolar only. The anchorage augmentation by ligation of the second premolar, first and second molars showed significant anchorage loss during canine retraction. Further randomized clinical trials are needed to investigate the effect of gingival fibrotomy on the rate of orthodontic tooth movement in non-extraction treatment.

Volume 50-December 2016 
Egyptian

Orthodontic Journal

\section{Appendix}

Table 2: Intraexaminer correlation coefficient of cast analysis of tooth movement.

\begin{tabular}{|l|l|l|l|l|}
\hline \multirow{2}{*}{} & \multirow{2}{*}{$\begin{array}{c}\text { Intraclass } \\
\text { Correlation }\end{array}$} & \multicolumn{2}{|c|}{$\mathbf{9 5 \%}$ Confidence Interval } & \\
\cline { 3 - 5 } & & Lower Bound & Upper Bound & P value \\
\hline Canine movement & 1.000 & 0.999 & 1.000 & 0.000 \\
\hline Molar movement & 1.000 & 0.999 & 1.000 & 0.000 \\
\hline
\end{tabular}

- Less than 0.40 poor.

- Between 0.40 and 0.59 Fair.

- Between 0.60 and 0.74 Good.

- Between 0.75 and 1.00 Excellent.

\section{REFERENCES}

1. Richter AE, Arruda AO, Peters MC, Sohn W. Incidence of caries lesions among patients treated with comprehensive orthodontics. Am. J. Orthod. Dentofac. Orthop. 2011;139(5):657-64.

2. Weltman B, Vig KWL, Fields HW, Shanker S, Kaizar EE. Root resorption associated with orthodontic tooth movement: a systematic review. Am. J. Orthod. Dentofacial Orthop. 2010;137(4):462-76; discussion 12A.

3. Yaffe A, Fine N, Binderman I. Regional accelerated phenomenon in the mandible following mucoperiosteal flap surgery. J. Periodontol. 1994;65:79-83.

4. Boese LR. Fiberotomy and reproximation without lower retention, nine years in retrospect: part I. Angle Orthod. 1980;50(2):88-97.

5. Tuncay OC, Killiany DM. The effect of gingival fiberotomy on the rate of tooth movement. Am. J. Orthod. 1986;89(3):212-5.

6. Glenn RW, Weimer AD, Wentz FM, Krejci RF. The effect of gingival fiberotomy on orthodontic cuspid retraction in cats. Angle Orthod. 1983;53(4):320-8.

7. Young L, Binderman I, Yaffe a, Beni L, Vardimon a D. Fiberotomy enhances orthodontic tooth movement and diminishes relapse in a rat model. Orthod. Craniofac. Res. 2013;16(3):161-8. 
Egyptian

Orthodontic Journal

8. Kalra A, Jaggi N, Bansal M, et al. Comparison of Rate of Canine Retraction into Recent Extraction Site with and without Gingival Fiberotomy: A Clinical Study. J. Contemp. Dent. Pract. 2013;14(3):419-26.

9. Sharma S, Kotrashetti SM. Accelerated osteogenic orthodontics (AOO): a prospective control study of corticotomy versus fiberotomy assisted orthodontic tooth movement. Int. J. Oral Maxillofac. Surg. 2015;44:e143-4.

10. Mezomo M, de Lima ES, de Menezes LM, Weissheimer A, Allgayer S. Maxillary canine retraction with self-ligating and conventional brackets. Angle Orthod. 2011;81(2):292-7.

11. Edwards JG. A surgical procedure to eliminate rotational relapse. Am. J. Orthod. 1970;57(1):35-46.

12. Limpanichkul W, Godfrey K, Srisuk N, Rattanayatikul C. Effects of low-level laser therapy on the rate of orthodontic tooth movement. Orthod. Craniofac. Res. 2006;9(1):38-43.

13. Abed SS, Al-Bustani AI. Corticotomy Assisted Orthodontic Treatment. J Bagh Coll. Dent. 2013;25(1):160-6.

14. Charoemratrote C, Leethanakul C. A Comparison of Effect of Regular Laceback Technique and Its Modification on Anchorage Loss. Songkanakarin Dent. J. 2013;1:18-25.

15. Leethanakul C, Kanokkulchai S, Pongpanich S, Leepong N, Charoemratrote $\mathrm{C}$. Interseptal bone reduction on the rate of maxillary canine retraction. Angle Orthod 2014;(October 2013).

16. Jang I, Tanaka M, Koga Y, et al. A Novel Method for the Assessment of Three-Dimensional Tooth Movement during Orthodontic Treatment. Angle Orthod. 2009;79(3):447-53.

17. Chen G, Chen S, Zhang XY, et al. Stable region for maxillary dental cast superimposition in adults, studied with the aid of stable miniscrews. Orthod. Craniofac. Res. 2011;14(2):70-9.

18. Wu J, Jiang J, Xu L, Liang C, Bai Y, Zou W. A pilot clinical study of Class III surgical patients facilitated by improved accelerated osteogenic orthodontic treatments. Angle Orthod. 2015;85(4):616-24. 
19. Frost HM. A 2003 update of bone physiology and Wolff s law for clinicians. Angle Orthod. 2004;74(1):3-15.

20. Gomez-Roman G. Influence of flap design on peri-implant interproximal crestal bone loss around single-tooth implants. Int. J. Oral Maxillofac. Implants 2000;16(1):61-7.

21. Binderman I, Bahar H, Yaffe A. Strain relaxation of fibroblasts in the marginal periodontium is the common trigger for alveolar bone resorption: a novel hypothesis. J. Periodontol. 2002;73(10):1210-5.

22. Nobuto $\mathrm{T}$, Imai $\mathrm{H}$, Suwa $\mathrm{F}$, et al. Microvascular response in the periodontal ligament following mucoperiosteal flap surgery. J. Periodontol. 2003;74(4):521-8.

23. Nobuto T, Suwa F, Kono T, et al. Microvascular response in the periosteum following mucoperiosteal flap surgery in dogs: Angiogenesis and bone resorption and formation. J. Periodontol. Periodontol. 2005;76(8):1346-53.

24. Binderman I, Bahar H, Jacob-Hirsch J, et al. P2X4 is up-regulated in gingival fibroblasts after periodontal surgery. J. Dent. Res. 2007;86(2):181-5.

25. Sebaoun J-D, Kantarci A, Turner JW, Carvalho RS, Van Dyke TE, Ferguson DJ. Modeling of trabecular bone and lamina dura following selective alveolar decortication in rats. J. Periodontol. 2008;79(9): 1679-88.

26. Binderman I, Gadban N, Bahar H, Herman A, Yaffe A. Commentary on: Periodontally accelerated osteogenic orthodontics (PAOO) - a clinical dilemma. Int. Orthod. 2010;8(3):268-77.

27. Burrow SJ. Canine retraction rate with self-ligating brackets vs conventional edgewise brackets. Angle Orthod. 2010;80(4):438-45. 